\title{
TU/e EnNHOUN

\section{Secondary ion mass spectrometry for the identification of polymers with noncharacteristic secondary ions using multivariate statistical analysis}

Citation for published version (APA):

Gennip, van, W. J. H., Thuene, P. C., Dijkstra, J. B., \& Niemantsverdriet, J. W. (2004). Secondary ion mass spectrometry for the identification of polymers with noncharacteristic secondary ions using multivariate statistical analysis. Applied Physics Letters, 84(10), 1789-1791. https://doi.org/10.1063/1.1642278

DOI:

10.1063/1.1642278

Document status and date:

Published: 01/01/2004

Document Version:

Publisher's PDF, also known as Version of Record (includes final page, issue and volume numbers)

Please check the document version of this publication:

- A submitted manuscript is the version of the article upon submission and before peer-review. There can be important differences between the submitted version and the official published version of record. People interested in the research are advised to contact the author for the final version of the publication, or visit the $\mathrm{DOI}$ to the publisher's website.

- The final author version and the galley proof are versions of the publication after peer review.

- The final published version features the final layout of the paper including the volume, issue and page numbers.

Link to publication

\footnotetext{
General rights

- You may freely distribute the URL identifying the publication in the public portal. follow below link for the End User Agreement:

www.tue.nl/taverne

Take down policy

If you believe that this document breaches copyright please contact us at:

openaccess@tue.nl

providing details and we will investigate your claim.
}

Copyright and moral rights for the publications made accessible in the public portal are retained by the authors and/or other copyright owners and it is a condition of accessing publications that users recognise and abide by the legal requirements associated with these rights.

- Users may download and print one copy of any publication from the public portal for the purpose of private study or research.

- You may not further distribute the material or use it for any profit-making activity or commercial gain

If the publication is distributed under the terms of Article 25fa of the Dutch Copyright Act, indicated by the "Taverne" license above, please 


\title{
Secondary ion mass spectrometry for the identification of polymers with noncharacteristic secondary ions using multivariate statistical analysis
}

\author{
W. J. H. van Gennip ${ }^{a)}$ and P. C. Thüne \\ Dutch Polymer Institute, Department of Physical Chemistry of Surfaces, HEW 3.48, \\ Eindhoven University of Technology, P.O. Box 513, 5600 MB Eindhoven, The Netherlands \\ J. B. Dijkstra \\ Department of Mathematics and Computer Science, Eindhoven University of Technology \\ J. W. Niemantsverdriet \\ Schuit Institute of Catalysis, Eindhoven University of Technology
}

(Received 8 August 2003; accepted 25 November 2003)

\begin{abstract}
Eleven different, filler-free polymers were depth profiled until all secondary ion signals were stable. Discriminant function analysis and principal components analysis were performed on a dataset containing the intensities of noncharacteristic hydrocarbon secondary ions, measured in this steady state. Discriminant function analysis showed that these secondary ions were sufficient to correctly identify all polymers using leave-one-out correction. Even with principal components analysis, which uses no prior knowledge about the origin of a data point, identification was shown to be possible. (C) 2004 American Institute of Physics. [DOI: 10.1063/1.1642278]
\end{abstract}

Secondary ion mass spectrometry is a powerful tool in the analysis of polymer surfaces. However, similarities in chemical composition, as, e.g., in polyethylene and polypropylene, make direct distinction by techniques based on mass spectrometry difficult, if not impossible. Multivariate statistical analysis ${ }^{1}$ of static SIMS spectra has already been applied to a multitude of problems, such as classification studies of adsorbed proteins, ${ }^{2-5}$ the study of their conformational changes upon adsorption, ${ }^{6,7}$ and other classification studies. ${ }^{8-10}$ All these studies used mass spectra measured during static sputter conditions. The main reason for this is that for high ion fluences, such as encountered during dynamic SIMS, any characteristic fragments that are most often used for multivariate statistical analysis are unstable. ${ }^{11} \mathrm{Nev}-$ ertheless, performing SIMS measurements under dynamic conditions may be desirable for the purpose of depth profiling.

However, the secondary ions produced by all common polymers (and hence noncharacteristic), such as the $\mathrm{C}_{n}^{-}$and the $\mathrm{C}_{n} \mathrm{H}^{-}$ions, are usually stable after equilibrium between the primary ions and the substrate has been reached. Although these secondary ions each by themselves do not contain any apparent information, these fragments together could contain enough information about the polymer to be able to identify it, for example the hydrogen to carbon ratio within each polymer, or because of different fragmentation pathways. Hence, it may be feasible to use these noncharacteristic hydrocarbon fragments to differentiate between mass spectra from different depth profiled polymers, with further differentiation from stable fragments containing other elements commonly encountered in polymers, such as oxygen and nitrogen. This study attempts to determine if this can be

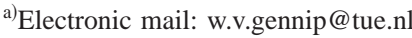

achieved using discriminant function analysis and principal components analysis.

Eleven common and filler-free polymers obtained from Goodfellow, shown in Fig. 1, polyethylene terephthalate (PET), polypropylene (PP), polymethylmethacrylate (PMMA), polyetheretherketone (PEEK), polybenzimidazole (PBI), polyethersulphone (PES), high density polyethylene (HDPE), polyamide-nylon 6 (PA 6), polyvinylchloride (PVC), polyimide (PI), and polyamide-nylon 6,6 (PA 6,6), were first cleaned with methylchloride, hexane, acetone and methanol, if they were not soluble in these solvents, to remove possible contamination from prior handling and storage. A thin gold layer of $\sim 30 \AA$ was deposited on top of all cleaned polymer samples by sputter coating to facilitate charge neutralization during depth profiling.

Depth profiles of all polymers were measured in a VG Ionex system equipped with a MIG-102 $\mathrm{Ga}^{+}$ion source, a LEG $31 \mathrm{~F}$ electron flood gun and a M12-2 s (<800 amu) quadrupole, using $10 \mathrm{keV} \mathrm{Ga}^{+}$primary ions for all measurements with an on-target current of $5.5 \mathrm{nA}$. An electronic gate was used that only allowed secondary ions originating from the center $10 \%$ of the total sputtered area to avoid crater wall effects. The depth profiles were continued until all secondary ion signals of interest were stable. From the stable part of each depth profile a selection was made of ten consecutive data points, and these were added to the dataset used for discriminant function and principal components analysis.

Because these measurements were performed on a quadrupole system, the secondary ions to be used for the discriminant function analysis had to be chosen in advance. To ensure normality of the ion intensity distribution, the intensity of each signal had to be high enough. The $\mathrm{C}^{-}, \mathrm{CH}^{-}, \mathrm{O}^{-}$, $\mathrm{OH}^{-}, \mathrm{C}_{2}^{-}, \mathrm{C}_{2} \mathrm{H}^{-}, \mathrm{C}_{2} \mathrm{H}_{2}^{-}$or $\mathrm{CN}^{-}, \mathrm{C}_{4}^{-}$, and $\mathrm{C}_{4} \mathrm{H}^{-}$ ions were chosen, because of the earlier mentioned hypothesis that the hydrocarbon ions together may contain informa- 


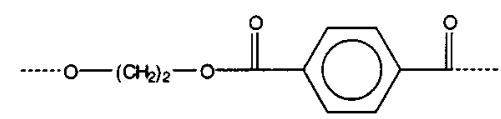

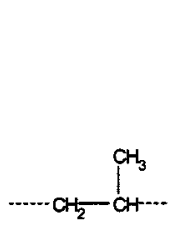

(b)

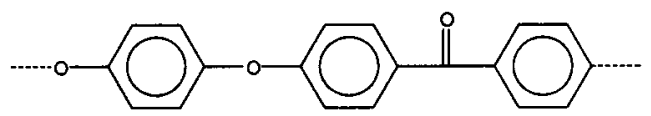

(d)

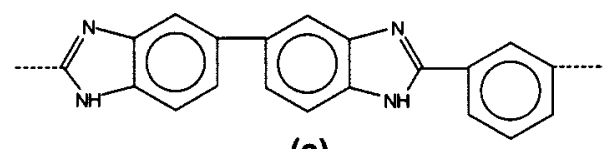

(e)

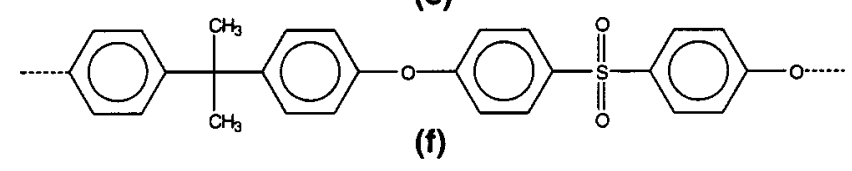

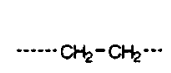

(g)
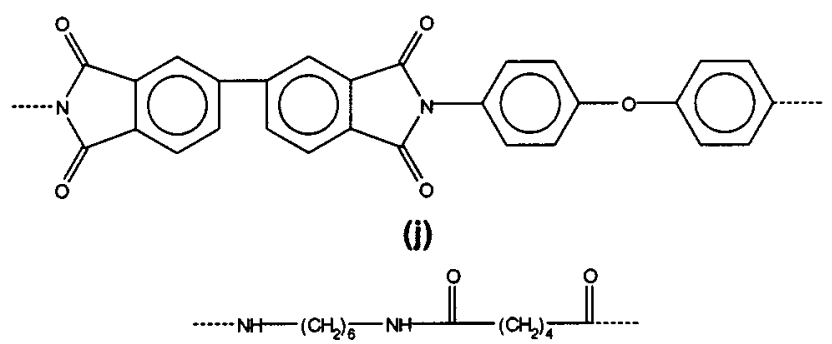

(k)
FIG. 1. Polymers used are (a) polyethylene terephthalate (PET), (b) polypropylene (PP), (c) polymethylmethacrylate (PMMA), (d) polyetheretherketone (PEEK), (e) polybenzimidazole (PBI), (f) polyethersulphone (PES), (g) high density polyethylene (HDPE), (h) polyamide-nylon 6 (PA 6), (i) polyvinylchloride (PVC), (j) polyimide (PI), (k) polyamide-nylon 6,6 (PA 6,6).

tion about the hydrogen to carbon ratio or the followed fragmentation pathways in the studied polymers.

It is important to note the essential difference between principal components analysis and discriminant function analysis. The latter emphasizes only the differences between different groups of measurements, whereas the former emphasizes the differences between all measurements, ignoring any prior knowledge. In both cases the hope is that all variation is captured in some few new variables $Z_{1}$ to $Z_{i}$.

First discriminant function analysis was performed on the complete dataset (eleven polymers; 110 data points) to see how well the chosen noncharacteristic secondary ions perform in separating the measurements of the different polymers. The first two functions shown captured $78.2 \%$ of the between-groups variance. Figure 2 shows that all eleven polymers were well separated using these first two functions, even though $21.8 \%$ of the information hidden in the intensities of the secondary ions measured was discarded in this figure. Using one function more would improve the separation only slightly. both Figs. 2 and 3. Also, when the loading of the first two
$\begin{aligned} & \text { tion only slightly. } \\ & \text { Downloaded } 05 \text { Apr } 2007 \text { to 131.155.151.48. Redistribution subject to AlP license or copyright, see http://apl.aip.org/apl/copyright.jsp }\end{aligned}$

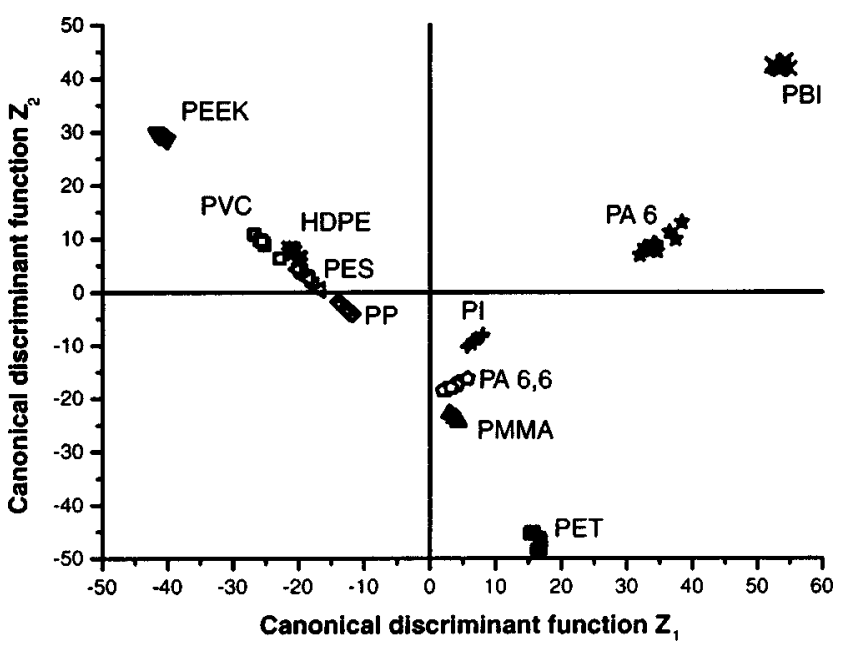

FIG. 2. Discriminant function analysis of the stable part of dynamic SIMS measurements of polymers $\mathbf{a}-\mathbf{k}$. The first two functions shown captured $78.2 \%$ of the between-groups variance.

To classify each measurement to one of the eleven groups, the so-called leave-one-out classification method was used. In this method each data point is classified by the functions derived from the complete dataset except that data point or case number, so that it cannot influence its own classification. All data points were correctly classified to the polymer they originated from, which proves that the chosen nonspecific secondary ions were together capable of distinguishing between the measured polymers.

Of course, the question is whether measurements can still be classified when no prior knowledge is assumed about the polymer they originate from. Principal component analysis was performed on the same dataset as used for the discriminant function analysis, using object principal normalization to normalize the dataset. This method optimizes distances between data points, which is useful when the differences or similarities between the data points are of interest. Figure 3(a) shows that even when no prior knowledge is used, most polymers can still readily be identified, with $74.6 \%$ of the total variance captured with the first two principal components. However, due to the nature of the principal components analysis, the groups of measurements that are rather different from the rest of the measurements influence the analysis rather much, so that polymers with nearidentical sub-datasets are grouped together. When PCA is performed on the dataset of only the six closest polymers in Fig. 3(a), these polymers can also be separated completely except for PP and PES, as shown in Fig. 3(b), with 73.4\% of the total variance captured. This proves that using nonspecific secondary hydrocarbon ions can be used to differentiate between different polymers even if no prior knowledge about the polymers is available.

The assumption that separation is based on the hydrogen to carbon ratio cannot be correct, because the polymers with more or less the same ratio are not close together in Figs. 2 and 3.

The assumption that different fragmentation pathways are at least partly responsible for the separation seems to have more merit. The purely aliphatic/vinylic polymers, i.e., HDPE, PP, and PVC, are consistently clustered together in 


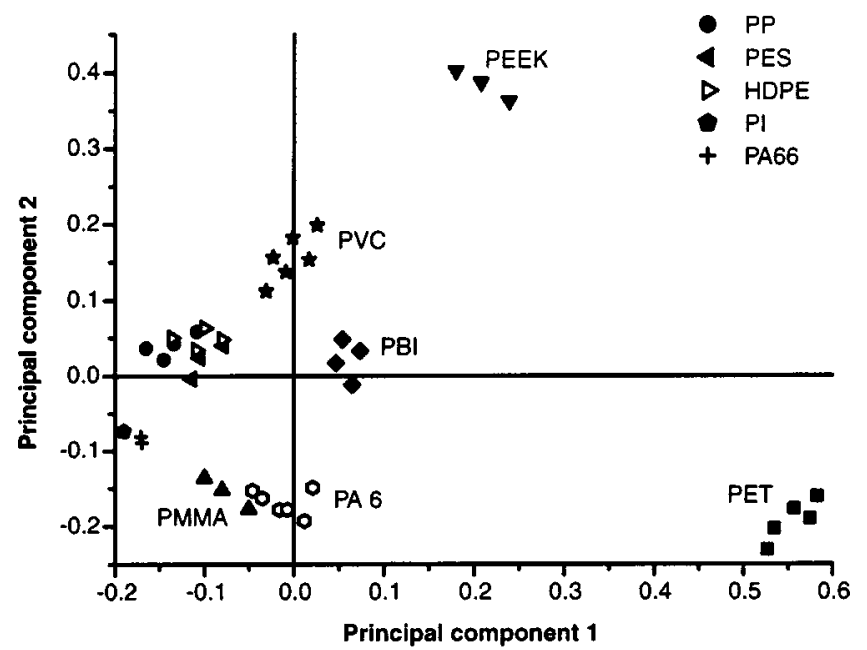

(a)

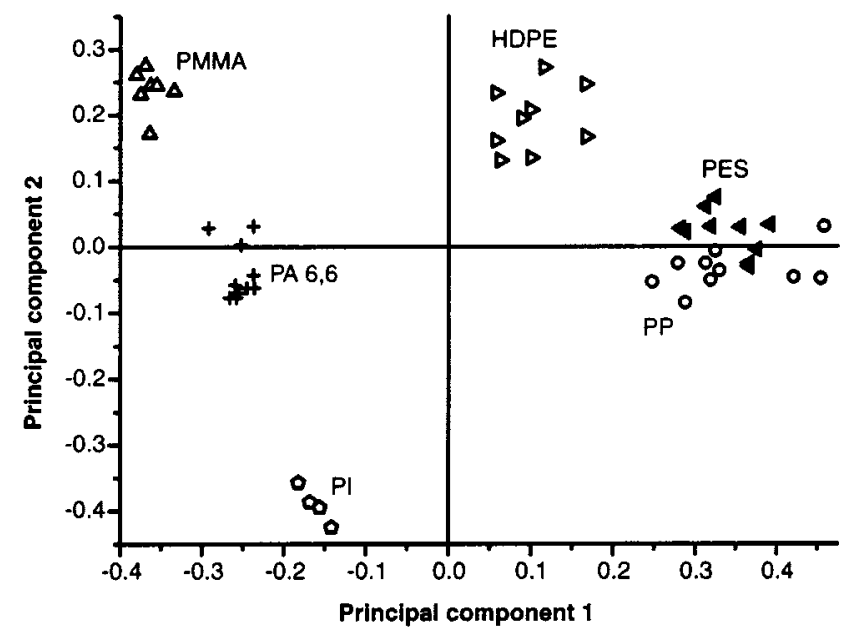

(b)

FIG. 3. (a) Principal components analysis of the stable part of dynamic SIMS measurements of polymers a-k. The first two principal components captured $74.6 \%$ of the total variance; (b) principal components analysis of the stable part of dynamic SIMS measurements of polymers $\mathbf{b}, \mathbf{c}, \mathbf{f}, \mathbf{g}, \mathbf{j}$, and k. The first two principal components captured $73.4 \%$ of the total variance.

principal components of the principal components analysis from Fig. 3(a) is studied, shown in Fig. 4, the higher-order hydrocarbon fragments, notably $\mathrm{C}_{2}$ and $\mathrm{C}_{2} \mathrm{H}$ but also $\mathrm{C}_{4}$ seem to contribute more to the second principal component, whereas the lower order fragments, such as $\mathrm{CH}$ and $\mathrm{C}$ contribute more to the first principal component, which could also suggest that the separation takes place on the basis of different fragmentation pathways.

In conclusion, a test on eleven common polymers showed that it is possible to distinguish between polymers by analyzing the intensities of nonspecific secondary hydrocarbon ions with discriminant function analysis or principal components analysis, if these secondary ions are measured after a steady-state between the primary ions and the polymer has been reached. Possibly these statistical methods could be used to identify fractions of polymers in depthprofiles of binary polymer blends, which would mean a large advance in the depth profiling of polymers.

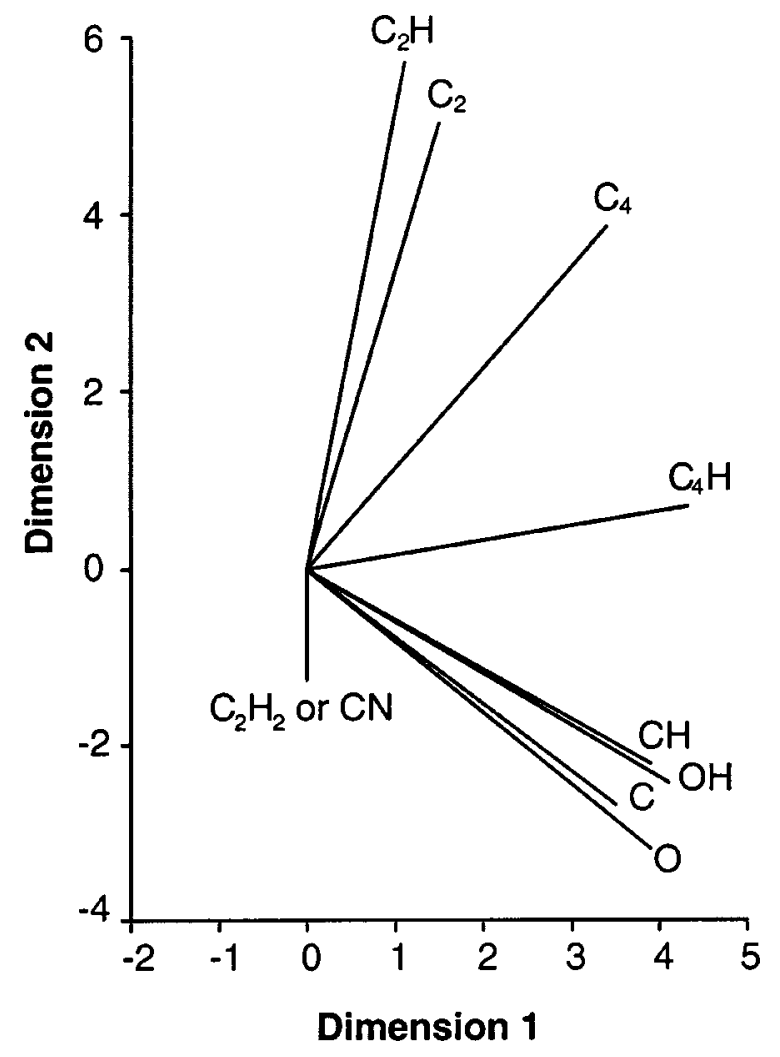

FIG. 4. Loading of the first two principal components.

However, the robustness of both methods needs to be studied, because for example a mass channel that shows a low intensity for all studied polymers may influence the statistical analysis unduly. The exact basis of the separation also remains unclear, although there is some indication that differences in fragmentation pathways play a role. Using ToFSIMS measurements will probably yield better results, because more and better resolved secondary ions can be used in the analysis.

${ }^{1}$ Principal Components Analysis, edited by I. T. Jolliffe (Springer, Berlin, 1986), pp. 1-271.

${ }^{2}$ M. C. Biesinger, P. Y. Paepegaey, N. S. McIntyre, R. R. Harbottle, and N. O. Petersen, Anal. Chem. 74, 5711 (2002).

${ }^{3}$ O. D. Sanni, M. S. Wagner, D. Briggs, D. G. Castner, and J. C. Vickerman Surf. Interface Anal. 33, 715 (2002).

${ }^{4}$ B. J. Tyler, A. Willse, and H. Shi, Proceedings of the Twelfth International Conference on Secondary Ion Mass Spectrometry (Elsevier, Amsterdam, 2000), pp. 943-946.

${ }^{5}$ M. S. Wagner and D. G. Castner, Langmuir 17, 4649 (2001).

${ }^{6}$ J. B. Lhoest, M. S. Wagner, C. D. Tidwell, and D. G. Castner, J. Biomed. Mater. Res. 57, 432 (2001).

${ }^{7}$ N. Xia, C. J. May, S. L. McArthur, and D. G. Castner, Langmuir 18, 4090 (2002).

${ }^{8}$ D. J. Graham, D. D. Price, and B. D. Ratner, Langmuir 18, 1518 (2002).

${ }^{9}$ G. Coullerez, D. Leonard, S. Lundmark, and H. J. Mathieu, Surf. Interface Anal. 29, 431 (2000).

${ }^{10} \mathrm{~F}$. Lang, Proceedings of the Twelfth International Conference on Secondary Ion Mass Spectrometry (Elsevier, Amsterdam, 2000), pp. 813-816.

${ }^{11} \mathrm{O}$. Brox, S. Hellweg, and A. Benninghoven, Proceedings of the Twelfth International Conference on Secondary Ion Mass Spectrometry (Elsevier, Amsterdam, 2000), pp. 777-780. 